Supporting Information

for

\title{
Insights into the Gelation Mechanism of
}

\section{Metal-Coordinated Hydrogels by Paramagnetic}

\section{NMR Spectroscopy and Molecular Dynamics}

Valeria Gabrielli,,$^{\dagger}$ Roberto Baretta, ${ }^{\dagger}$ Roberto Pilot, ${ }^{\dagger+t}$ Alberta Ferrarini ${ }^{\dagger}$ and Marco Frasconi ${ }^{*}{ }^{\dagger}$

${ }^{\dagger}$ Department of Chemical Sciences, University of Padova, Via Marzolo 1, 35131Padova, Italy. Consorzio INSTM, Via G. Giusti 9, I-50121 Firenze, Italy.

Table of Contents

1. Results. .52

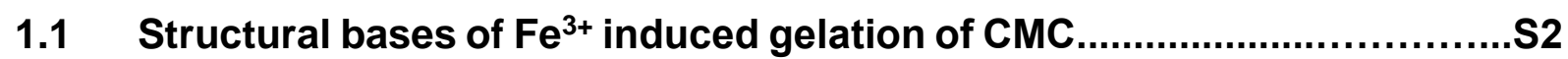

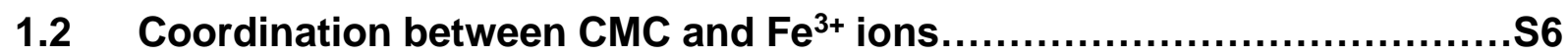

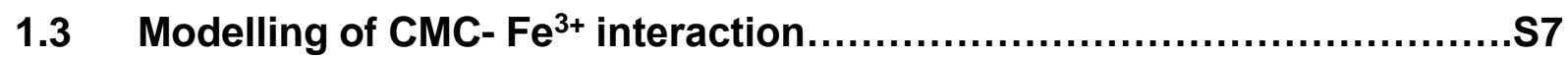

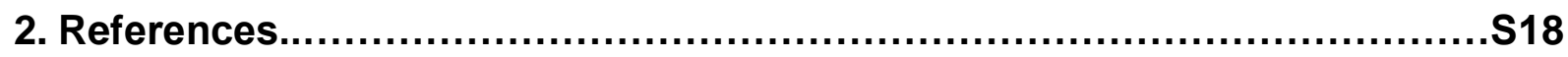




\section{Results}

\subsection{Structural bases of $\mathrm{Fe}^{3+}$ induced gelation of $\mathrm{CMC}$ \\ 1.1.1 Molecular interaction of $\mathrm{Fe}^{3+}$ ions with CMC}

To achieve atomistic details on the $\mathrm{CMC}-\mathrm{Fe}^{3+}$ interaction, we exploited the paramagnetic nature of $\mathrm{Fe}^{3+}$ ions. ${ }^{13} \mathrm{C}$ HSQC spectra were assigned on the bases of previous studies ${ }^{1-4}$ (Figure S1). Interactions between $\mathrm{CMC}$ and $\mathrm{Fe}^{3+}$ ions were monitored thanks to the distance dependent paramagnetic relaxation enhancement induced by the presence of $\mathrm{Fe}^{3+}$ ions in a $\mathrm{CMC}$ sample. We performed experiments on $\mathrm{CMC}$ with different $\mathrm{DS}$ (see main text), keeping constant the $\mathrm{Fe}^{3+}$ concentration. For CMC with DS 0.9 we performed titration experiments where the $\mathrm{Fe}^{3+}$ concentration was gradually incremented in a CMC $1 \% \mathrm{w} / \mathrm{V}$ sample.

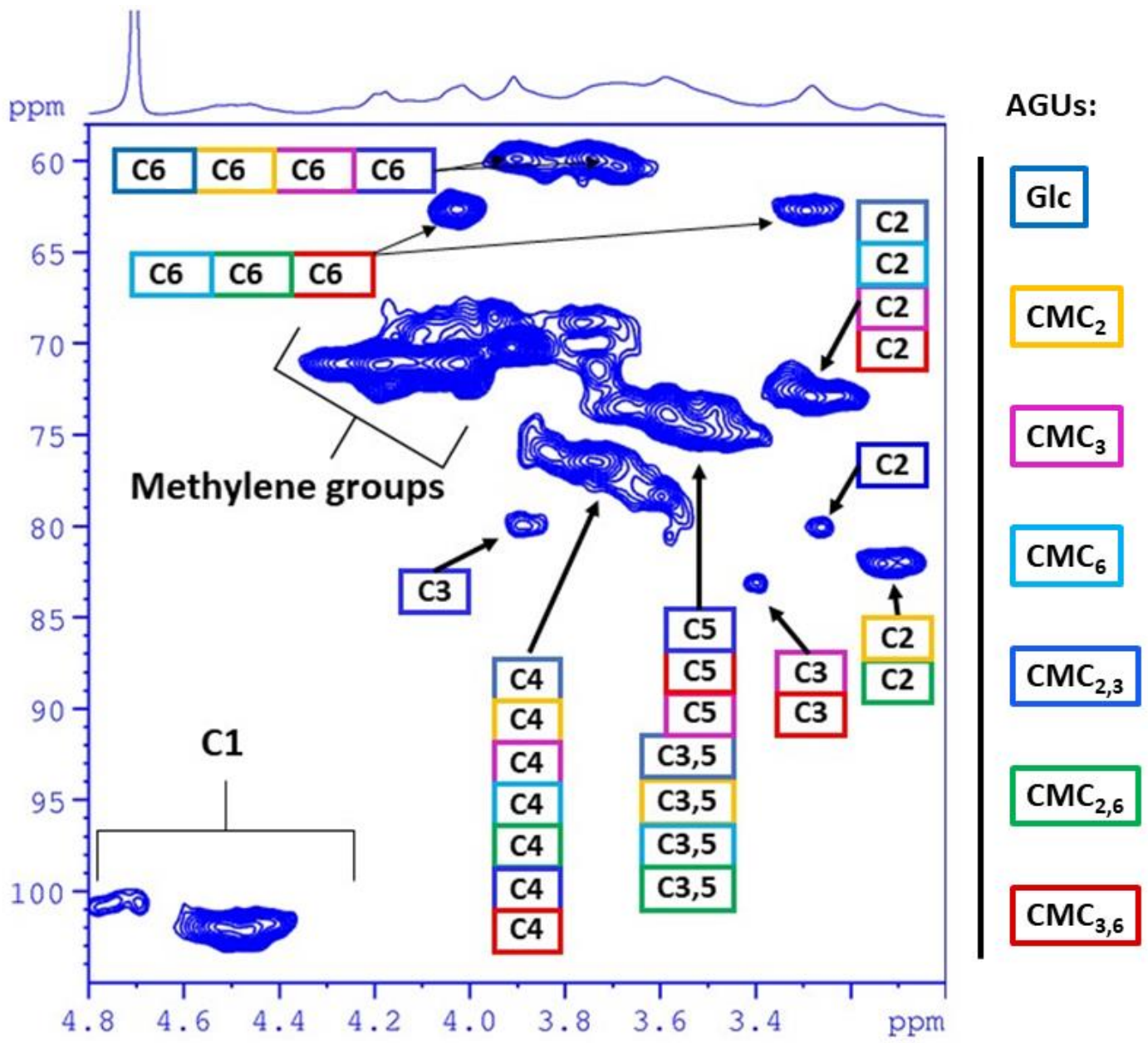

Figure S1. ${ }^{13} \mathrm{C} \mathrm{HSQC}$ spectra with chemical shift assignment of CMC with a DS of 0.9. The unambiguous peaks of $\mathrm{C} 2$ and $\mathrm{C} 3$ of the 2,3-disubstituted CMC were detected for all the investigated DS. 
Table S1. Ratio between the C peaks integrals of CMC (DS 0.9) $1 \% \mathrm{w} / \mathrm{V}$ in the presence of $\mathrm{Fe}^{3+}(0.5$, $0.75,1$ and $5 \mathrm{mM}$ final concentration) and in the absence of $\mathrm{Fe}^{3+}$.

\begin{tabular}{|c|c|c|c|c|c|c|c|c|c|}
\hline & & \multicolumn{8}{|c|}{ CMC AGUs } \\
\hline \multicolumn{2}{|c|}{$\begin{array}{c}\text { CMC DS } 0.9 \\
1 \% \mathrm{w} / \mathrm{V}\end{array}$} & $\begin{array}{c}\text { CMC } \\
2 \\
2,6\end{array}$ & $\begin{array}{c}\text { CMC } \\
2,3\end{array}$ & $\begin{array}{c}C M C \\
3 \\
6 \\
3,6 \\
\end{array}$ & $\begin{array}{c}\mathrm{CMC} \\
\mathbf{3} \\
\mathbf{3 , 6}\end{array}$ & $\begin{array}{c}\text { CMC } \\
2,3\end{array}$ & $\begin{array}{c}\text { CMC } \\
6 \\
2,6 \\
3,6 \\
\end{array}$ & $\begin{array}{c}\text { CMC } \\
6 \\
2,6 \\
3,6 \\
\end{array}$ & $\begin{array}{c}\mathrm{CMC} \\
2 \\
3 \\
2,3 \\
\end{array}$ \\
\hline$\left[\mathrm{Fe}^{3+}\right](\mathrm{mM})$ & $C 1$ & $C 2$ & $C 2$ & $C 2$ & C3 & C3 & C6 & $C 6^{\prime}$ & C6 \\
\hline 0 & 1 & 1 & 1 & 1 & 1 & 1 & 1 & 1 & 1 \\
\hline 0.5 & 0.92 & 1.02 & 0.92 & 0.64 & 1.03 & 0.93 & 1.06 & 0.84 & 0.91 \\
\hline 0.75 & 0.94 & 1.05 & 0.97 & 0.81 & 0.94 & 0.68 & 0.89 & 0.82 & 0.88 \\
\hline 1 & 0.84 & 0.98 & 0.54 & 0.66 & 0.59 & 0.62 & 0.90 & 0.84 & 0.84 \\
\hline 5 & 0.60 & 0.77 & ns & 0.67 & ns & ns & 0.45 & 0.30 & 0.74 \\
\hline
\end{tabular}

Table S2. Signal intensity decay for the carboxymethyl substitutions in the glucopyranose unit of CMC with different DS using a relaxation delay of $21.5 \mathrm{~s}$.

\begin{tabular}{|c|c|c|c|c|c|c|c|c|c|}
\hline $\begin{array}{l}\text { CMC } \\
\text { (DS) }\end{array}$ & & $\begin{array}{c}\text { CMC } \\
2 \\
2,6\end{array}$ & $\begin{array}{c}\text { CMC } \\
2,3\end{array}$ & $\begin{array}{c}\text { CMC } \\
3 \\
6 \\
3,6\end{array}$ & $\begin{array}{c}\text { CMC } \\
3 \\
3,6\end{array}$ & $\begin{array}{c}\text { CMC } \\
2,3\end{array}$ & $\begin{array}{c}\text { CMC } \\
6 \\
2,6 \\
3,6\end{array}$ & $\begin{array}{c}\text { CMC } \\
6 \\
2,6 \\
3,6\end{array}$ & $\begin{array}{c}\text { CMC } \\
2 \\
3 \\
2,3\end{array}$ \\
\hline & $C 1$ & $C 2$ & $C 2$ & $C 2$ & C3 & C3 & $C \sigma^{\prime}$ & $C 6^{\prime \prime}$ & C6 \\
\hline 0.7 & 1.35 & 1.47 & ns & 1.55 & ns & ns & 0.64 & 0.50 & 1.11 \\
\hline 0.9 & 1.20 & 0.94 & ns & 0.87 & ns & ns & 0.43 & 0.33 & 0.73 \\
\hline 1.2 & 1.13 & 0.71 & ns & 1.03 & ns & ns & 0.32 & 0.36 & 0.76 \\
\hline
\end{tabular}

ns = no signal 


\subsubsection{The presence of $\mathrm{Fe}^{3+}$ ions induces water structuration in CMC}

The CMC-Fe ${ }^{3+}$-water interaction was monitored by collection of the HDO STD NMR build-up curves and then further application of the Spin Diffusion Transfer Difference (SDTD) NMR protocol, which allowed us to unveil changes in water structuration upon introduction of $\mathrm{Fe}^{3+}$ ions.

a)

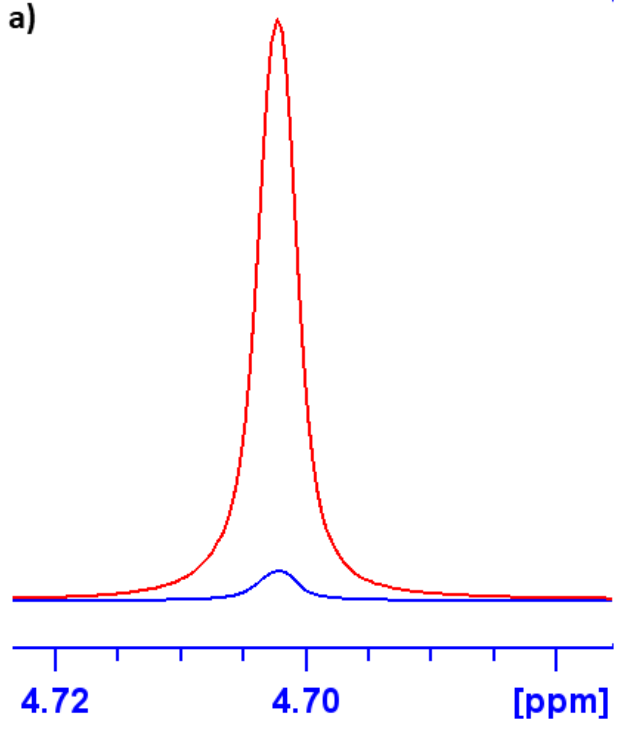

b)

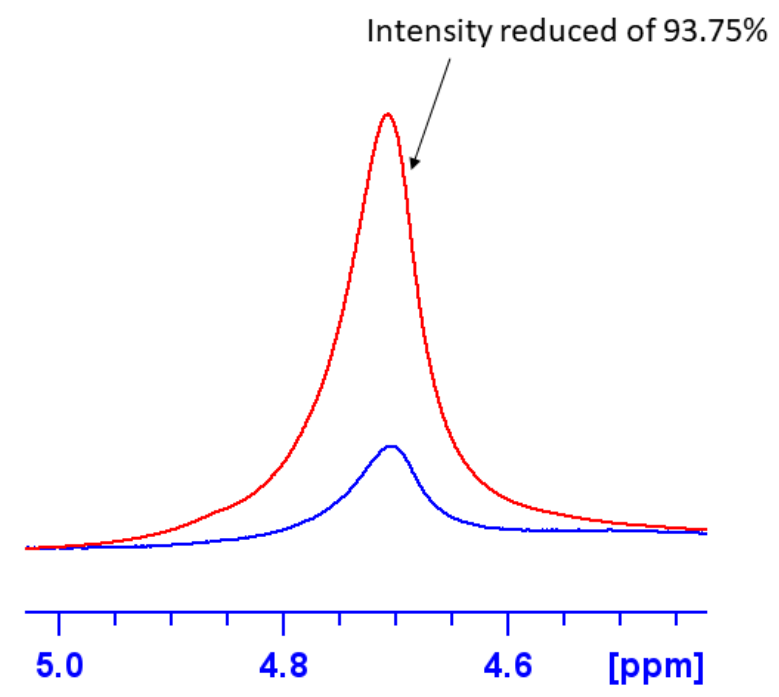

Figure S2. Off-Resonance (red) and STD (blue) HDO peak for CMC (DS 0.7) $1 \% \mathrm{w} / \mathrm{V}$ dispersion in the absence (a) and in the presence (b) of $\mathrm{Fe}^{3+}$ ions $\left(\mathrm{Fe}\left(\mathrm{NO}_{3}\right)_{3}, 5 \mathrm{mM}\right)$. The spectra were recorded at $298 \mathrm{~K}$ and at $20 \mathrm{~s}(\mathrm{a})$ and $8 \mathrm{~s}(\mathrm{~b})$ saturation times. 
Table S3. Calculated values for the $C$ and $D$ parameters obtained from the fit to Equation 1 of the SDTD build-up curves of the HDO peak for the CMC (DS 0.7) $1 \% \mathrm{w} / \mathrm{v}$ dispersions without and with the presence of $\mathrm{Fe}^{3+}$ ions. An $r$ value of $0.2 \mathrm{~nm}$ and a $b$ value of 2 were kept constant during the fit. For the $b$ parameter, several values were tested to achieve the best fit. The errors associated to each $C$ and $D$ value are shown in parenthesis and correspond to the $99 \%$ confidence level. The $\mathrm{R}^{2}$ values of each fit to Equation 1 (main text) are shown.

\begin{tabular}{|l|l|l|}
\hline & CMC (DS 0.7) 1\% w/V & CMC (DS 0.7) 1\% w/V with Fe $\mathbf{F}^{3+} \mathbf{~ m M}$ \\
\hline $\mathbf{C}$ & $0.804( \pm 0.07)$ & $0.623( \pm 0.04)$ \\
\hline $\mathbf{D}\left(\mathrm{nm}^{2} / \mathrm{ms}\right)$ & $2.29 \mathrm{E}-05( \pm 1.8 \mathrm{E}-06)$ & $6.38 \mathrm{E}-05( \pm 5.91 \mathrm{E}-06)$ \\
\hline $\mathbf{R}^{2}$ & 0.9961 & 0.9934 \\
\hline
\end{tabular}

Table S4. Calculated values for the $C$ and $D$ parameters obtained from the fit to Equation 1 of the SDTD build-up curves of the HDO peak for the CMC (DS 0.9) $1 \% \mathrm{w} / \mathrm{V}$ dispersions without and with the presence of $\mathrm{Fe}^{3+}$ ions. An $r$ value of $0.2 \mathrm{~nm}$ and a $b$ value of 2 were kept constant during the fit. For the $b$ parameter, several values were tested to achieve the best fit. The errors associated to each $C$ and $D$ value are shown in parenthesis and correspond to the $99 \%$ confidence level. The $\mathrm{R}^{2}$ values of each fit to Equation 1 (main text) are shown.

\begin{tabular}{|l|l|l|}
\hline & CMC (DS 0.9) 1\% w/V & CMC (DS 0.9) 1\% w/V with Fe $\mathbf{~}^{3+} \mathbf{~ m M}$ \\
\hline$C$ & $0.803( \pm 0.06)$ & $0.58( \pm 0.03)$ \\
\hline $\mathbf{D}\left(\mathbf{n m}^{2} / \mathbf{m s}\right)$ & $2.28 \mathrm{E}-05( \pm 1.64 \mathrm{E}-06)$ & $7.43 \mathrm{E}-05( \pm 6.53 \mathrm{E}-06)$ \\
\hline $\mathbf{R}^{\mathbf{2}}$ & 0.9967 & 0.994 \\
\hline
\end{tabular}

Table S5. Calculated values for the $C$ and $D$ parameters obtained from the fit to Equation 1 of the SDTD build-up curves of the HDO peak for the CMC (DS 1.2) $1 \% \mathrm{w} / \mathrm{V}$ dispersions without and with the presence of $\mathrm{Fe}^{3+}$ ions. An $r$ value of $0.2 \mathrm{~nm}$ and a $b$ value of 2 were kept constant during the fit. For the $b$ parameter, several values were tested to achieve the best fit. The errors associated to each $C$ and $D$ value are shown in parenthesis and correspond to the $99 \%$ confidence level. The $\mathrm{R}^{2}$ values of each fit to Equation 1 (main text) are shown.

\begin{tabular}{|l|l|l|}
\hline & CMC (DS 1.2) 1\% w/V & CMC (DS 1.2) 1\% w/V with Fe ${ }^{3+} \mathbf{~ m M ~}$ \\
\hline C & $0.804( \pm 0.06)$ & $0.59( \pm 0.04)$ \\
\hline $\mathbf{D}\left(\mathbf{n m}^{2} / \mathbf{m s}\right)$ & $2.29 \mathrm{E}-05( \pm 1.56 \mathrm{E}-06)$ & $6.98 \mathrm{E}-05( \pm 7.53 \mathrm{E}-06)$ \\
\hline $\mathbf{R}^{\mathbf{2}}$ & 0.9961 & 0.9908 \\
\hline
\end{tabular}




\subsection{Coordination between $\mathrm{CMC}$ and $\mathrm{Fe}^{3+}$ ions}

Table S6. Position of vibrational peaks of CMC observed by Raman spectroscopy with respective assignments. ${ }^{5}$

\begin{tabular}{|l|l|}
\hline Raman Shift $\left(\mathbf{c m}^{-1}\right)$ & Band assignment \\
\hline $1477-1455$ & $\left(\mathrm{CH}_{2}\right)$ methylene bending vibrations \\
\hline $1295-1265$ & $\left(\mathrm{CH}_{2}\right)$ methylene twisting mode \\
\hline $1120-1116$ & $(\mathrm{COC})$ glycosidic stretching; ring breathing \\
\hline 1095 & $(\mathrm{COC})$ glycosidic stretching; ring breathing \\
\hline $380-355$ & $(\mathrm{CCC}),(\mathrm{CO}),(\mathrm{CCO})$ ring deformation \\
\hline 1611 and 1416 & $\begin{array}{l}(\mathrm{COO}) \text { asymmetric and symmetric carbonyl } \\
\text { stretching vibrations }\end{array}$ \\
\hline 1338 & $\begin{array}{l}\text { Asymmetric wagging vibrations of methylene } \\
(\mathrm{CH}\end{array}$ \\
at $\mathrm{C}_{2}$ ) assigned to hydroxymethylene side chain \\
\hline $1330-1320$ & $\begin{array}{l}\text { Wagging vibrations of methylene }\left(\mathrm{CH}_{2}\right) \text { adjacent } \\
\left.\text { to an ether group (- } \mathrm{CH}_{2} \mathrm{OR}\right)\end{array}$ \\
\hline
\end{tabular}


a) Single chain

2,'3'-carboxymethyl cellotriose

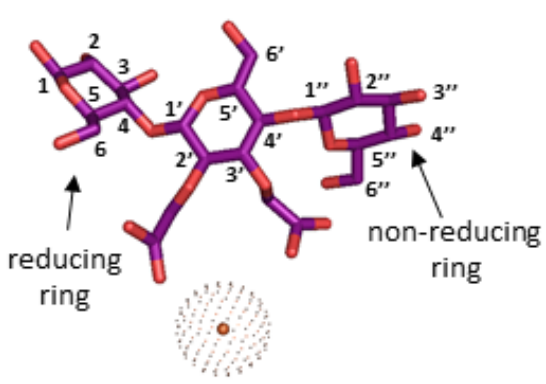

b) Double chains 2',6'-carboxymethyl cellotriose

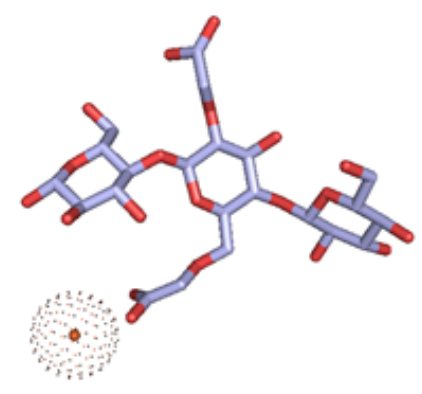

3',6'-carboxymethyl cellotriose

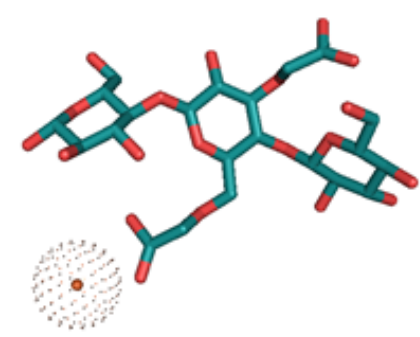

2'-mono/2'-mono

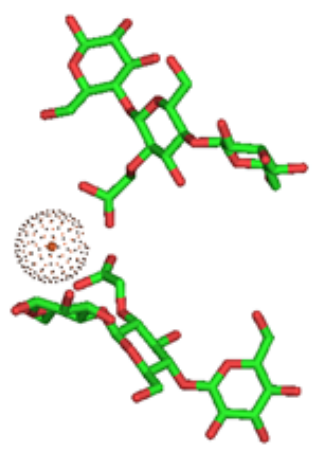

2'-mono/6'-mono

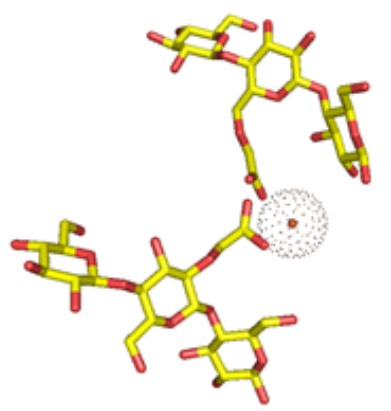

2'-mono/3'-mono

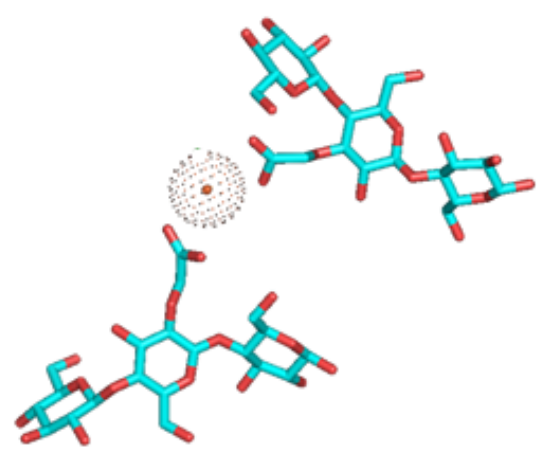

3'-mono/6'-mono

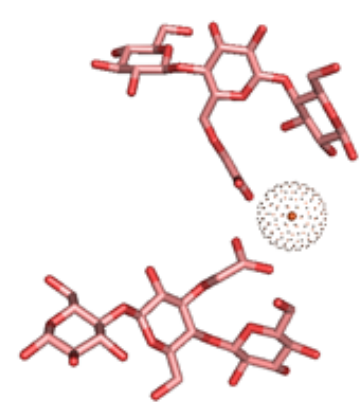

3'-mono/3'-mono

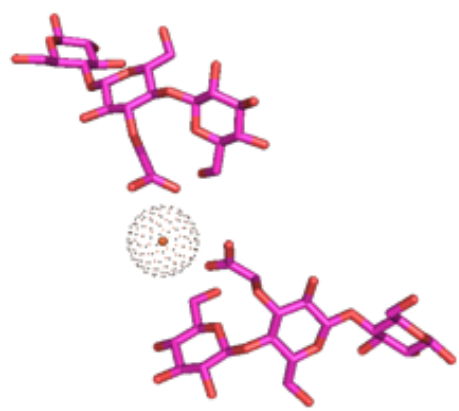

6'-mono/6'-mono

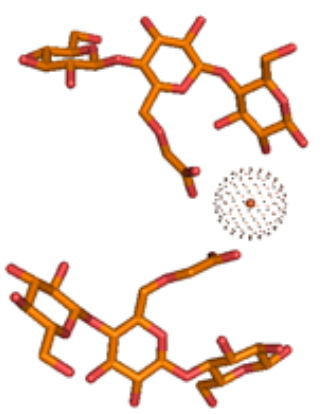

Figure S3. Structural representation of the starting configurations used in the MD simulation of the carboxymethyl-substituted cellotriose systems coordinated to $\mathrm{Fe}^{3+}$ by single chain (a) and double chain (b). In Figure a) the ring position numbers are reported, and the reducing and non-reducing rings indicated for the $2^{\prime}, 3^{\prime}$-carboxymethyl cellotriose system. 

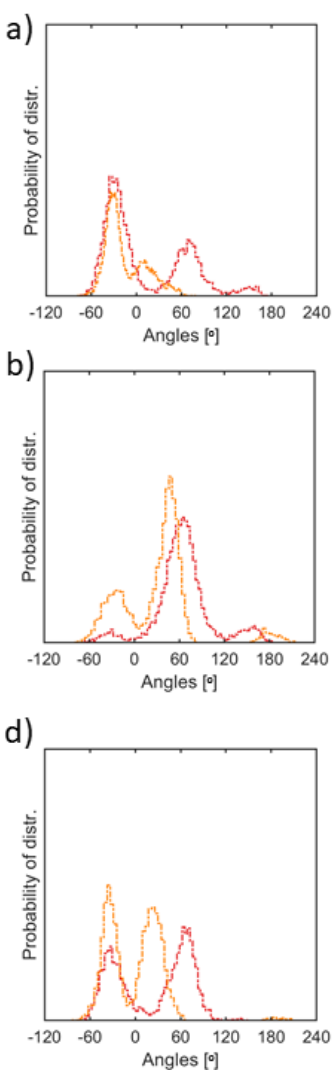
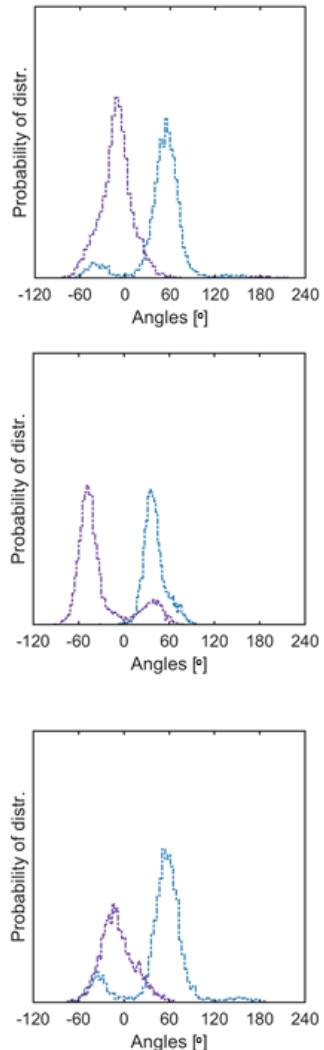
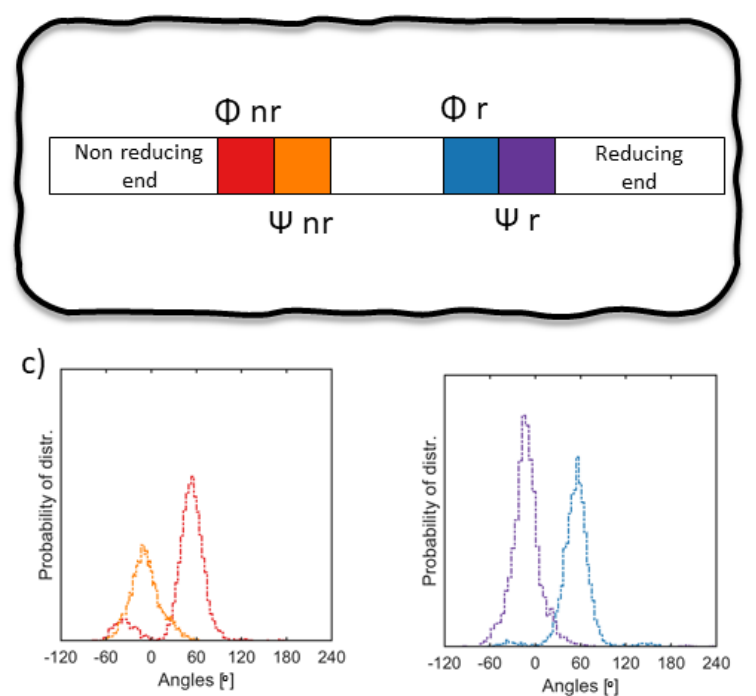

e)
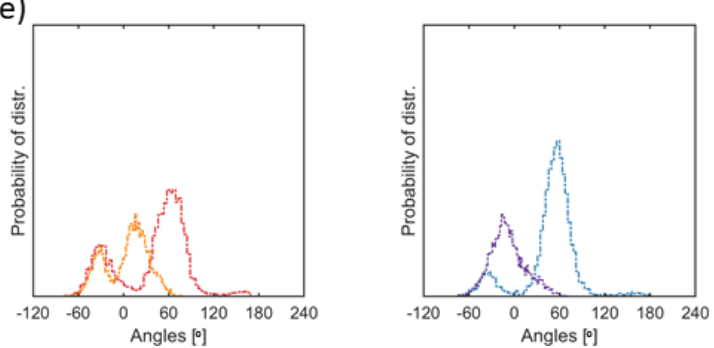

Figure S4. Probability distribution of the inter-glycosidic linkages dihedral angles $\Phi$ (red toward the non-reducing ring terminal and blue toward the reducing ring terminal) and $\Psi$ (orange toward the nonreducing ring terminal and purple toward the reducing ring terminal). From (a) to (e) dihedrals of the single chain disubstituted system: a) 2',3'-dicarboxymethyl-cellotriose, b) 2',6'-dicarboxymethylcellotriose without restraints, c) 2',6'-dicarboxymethyl-cellotriose with restraints on the central ring to avoid ring flip artifacts, d) $3^{\prime}, 6^{\prime}$-dicarboxymethyl-cellotriose with the $\mathrm{Fe}^{3+}$ ion bonded to the carboxymethyl group in $\mathrm{C} 6$, e) $3^{\prime}, 6^{\prime}$-dicarboxymethyl-cellotriose with the $\mathrm{Fe}^{3+}$ ion bonded to the carboxymethyl group in C3. 

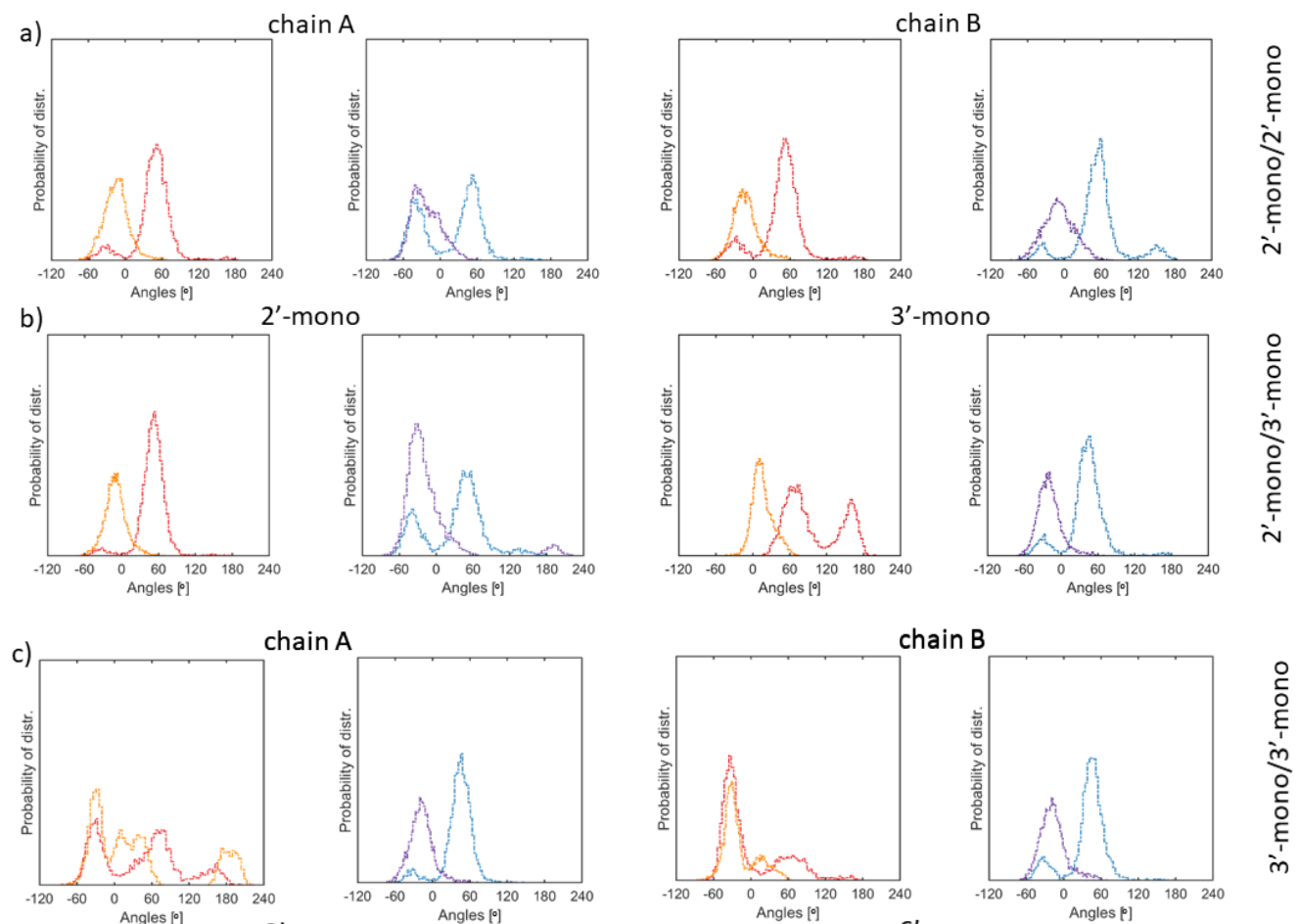

chain A
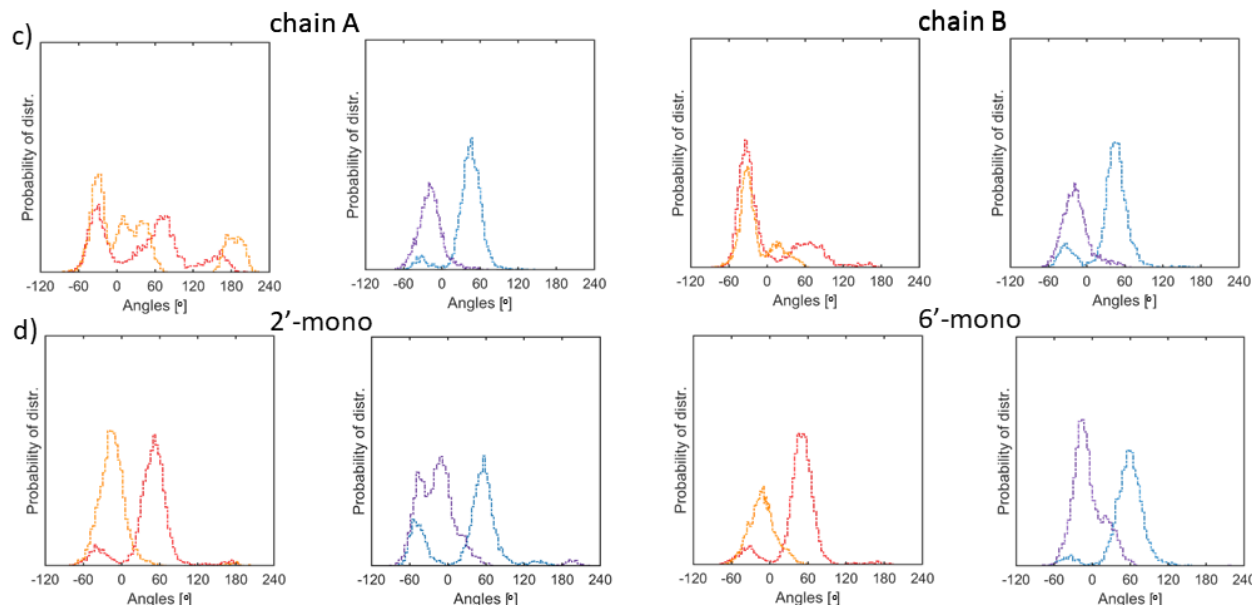

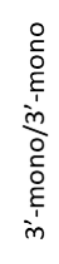
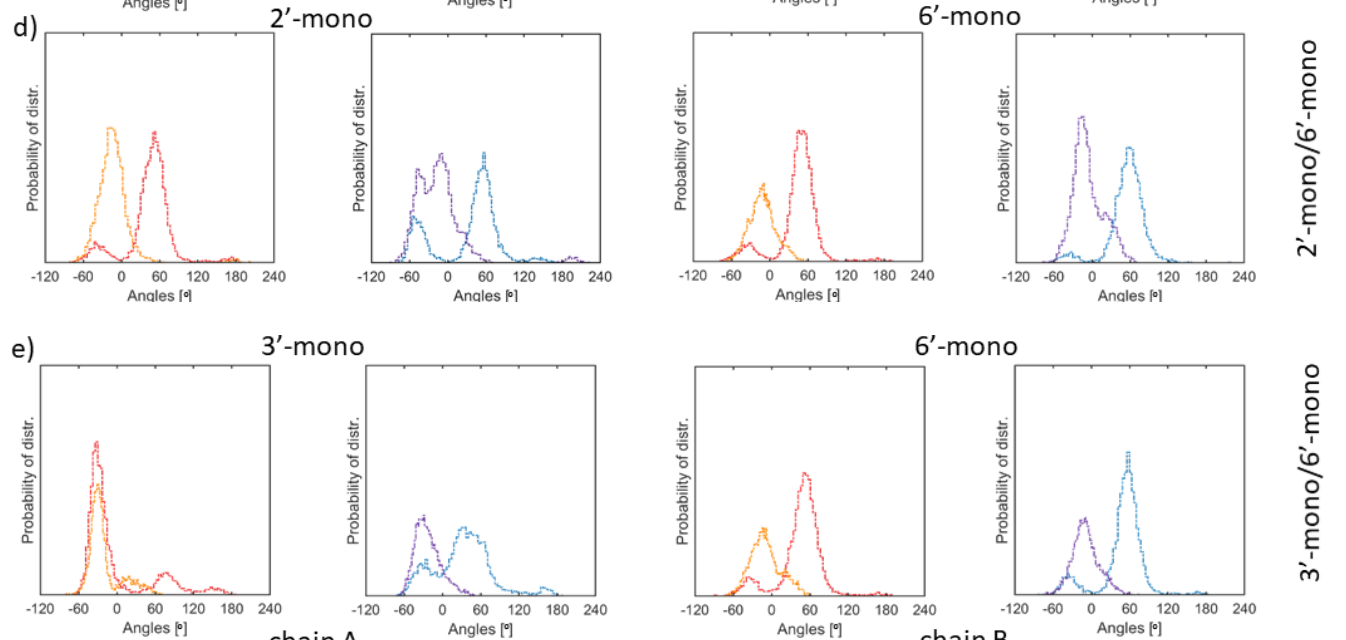

3'-mono
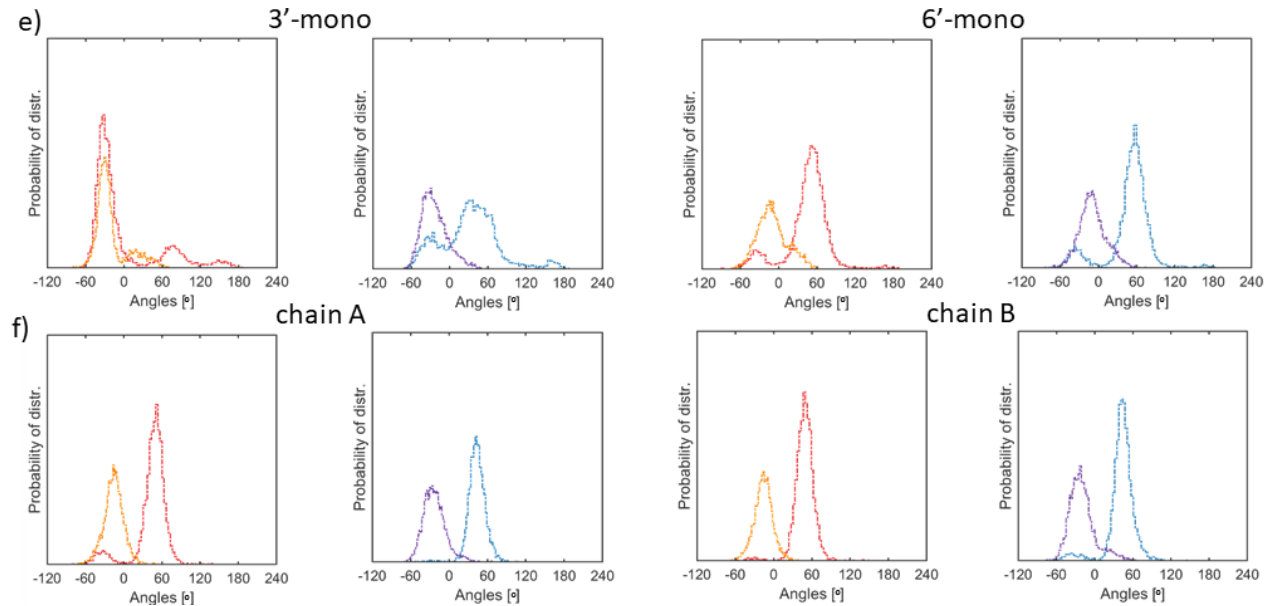

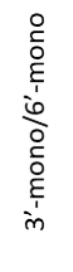
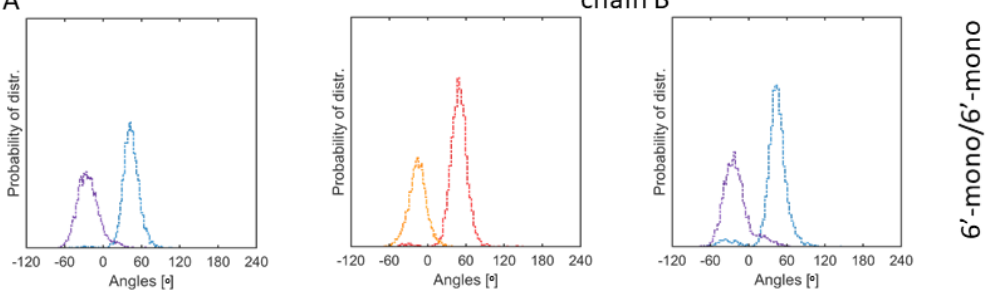

Figure S5. Probability distribution of the inter-glycosidic linkages dihedral angles $\Phi$ (red toward the non-reducing ring terminal and blue toward the reducing ring terminal) and $\Psi$ (orange toward the nonreducing ring terminal and purple toward the reducing ring terminal, see also Figure S4). From (a) to (f) dihedrals of the double chains monosubstituted system: a) 2'-mono/2'mono, b) 2'-mono/3'-mono, c) 3'-mono/3'-mono, d)2'-mono/6'-mono, e) 3'-mono/6'-mono and f) 6'-mono/6'-mono. 


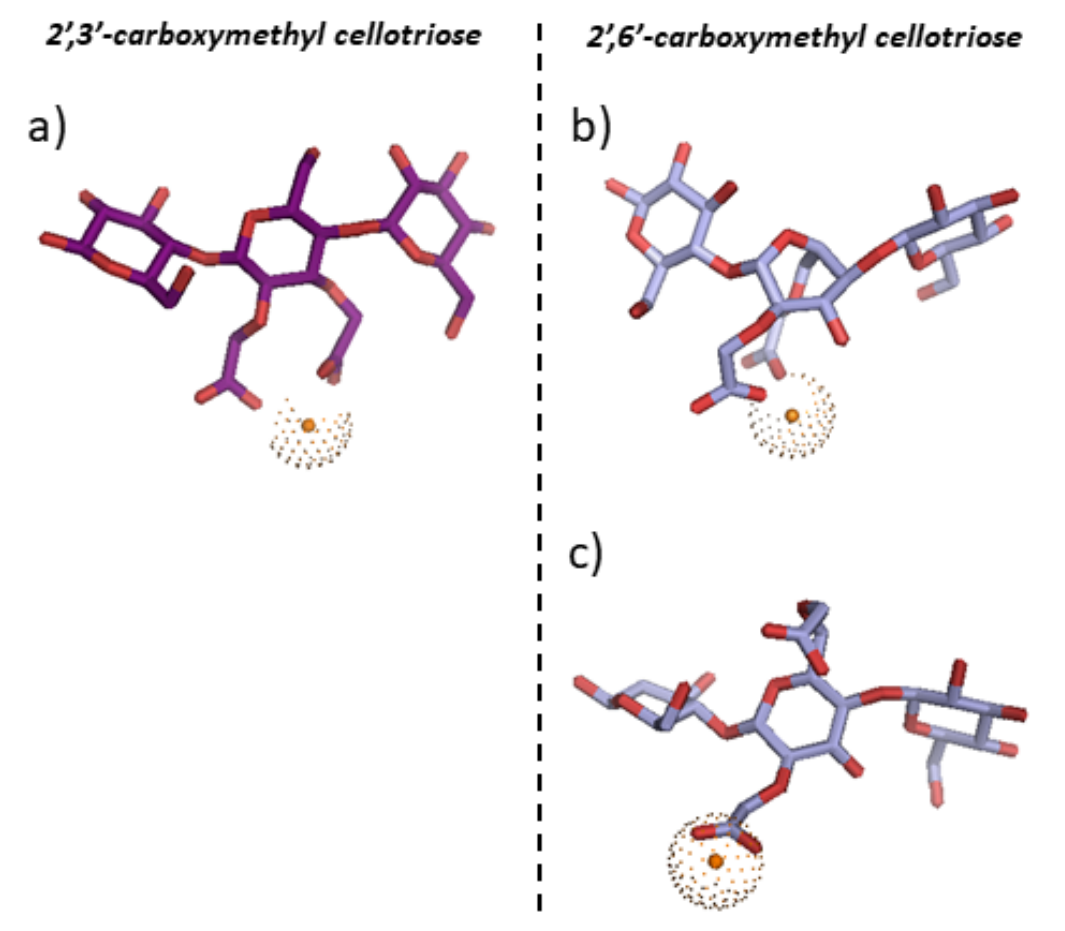

3',6'-carboxymethyl cellotriose

d)

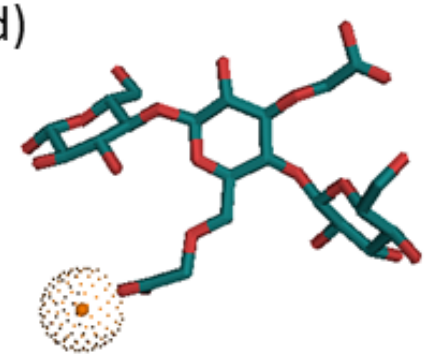

e)

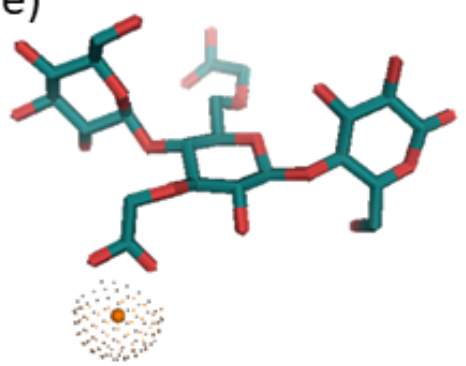

Figure S6. Final configurations of 100 ns MD trajectories simulated for (a) 2', $3^{\prime}-$, (b and c) $2^{\prime}, 6^{\prime}$ and (c and d) 3',6'-carboxymethyl cellotriose systems. For the 2' $6^{\prime}$ - and the $3^{\prime}, 6^{\prime}$-carboxymethyl cellotriose derivatives, two simulations were performed. In the 2',6'-carboxymethyl cellotriose derivative, simulations without (b) and with (c) a conformational restraint on the central ring were performed. For the $3^{\prime}, 6^{\prime}$-carboxymethyl cellotriose derivative, instead, we performed two simulations with the $\mathrm{Fe}^{3+}$ ion located in proximity of the carboxymethyl group in position C6 (d) and C3 (e). The structures have been extracted from VMD and then represented using Pymol. Carboxymethyl-cellotriose systems are represented as tubes, while the $\mathrm{Fe}^{3+}$ ion as dotted spheres.

Table S7. Average distance between the $\mathrm{Fe}^{3+}$ ion and the carbons of the central ring of $2^{\prime}, 3^{\prime}-$ carboxymethyl-cellotriose.

\begin{tabular}{c|cc} 
Carbon & Average Distance [A] & Standard deviation \\
\hline C1 & 6.46 & 0.27 \\
C2 & 5.24 & 0.21 \\
C3 & 5.29 & 0.24 \\
C4 & 6.76 & 0.25 \\
C5 & 7.65 & 0.32 \\
C6 & 9.07 & 0.40
\end{tabular}




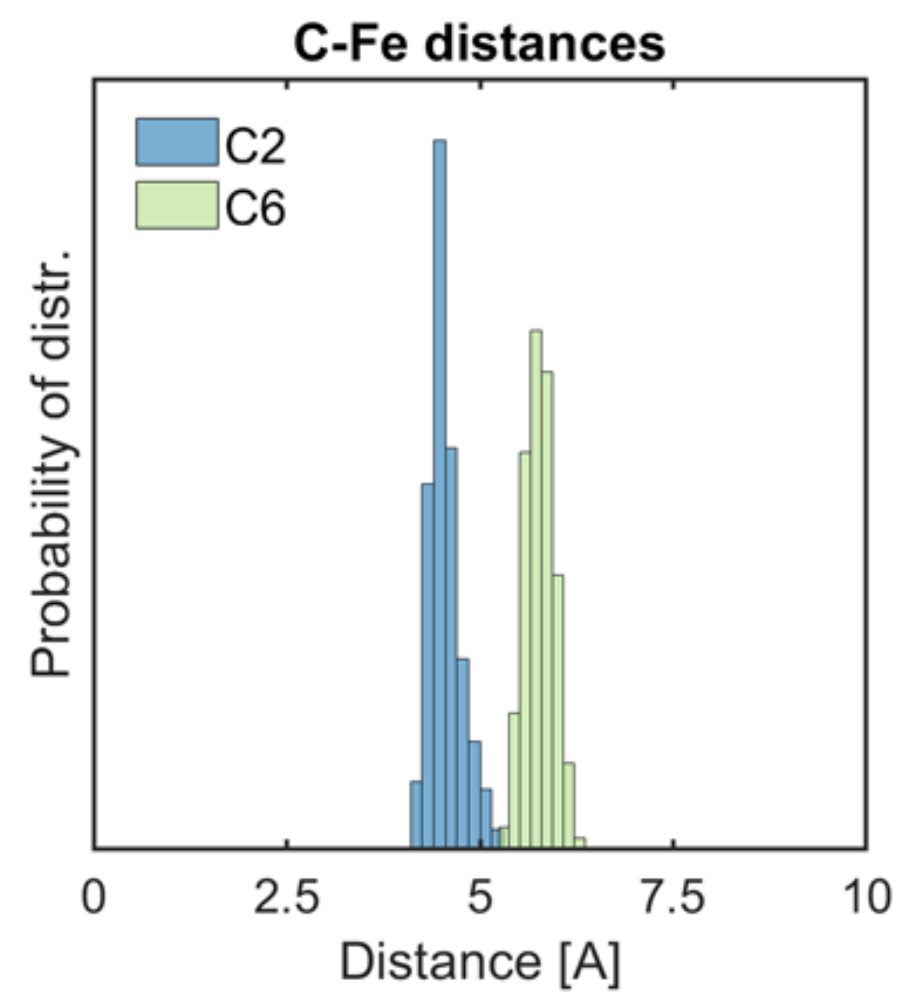

Figure S7. Histograms of the distance between the $\mathrm{Fe}^{3+}$ ion and the carbons $\mathrm{C2}$ (pale blue) and $\mathrm{C} 6$ (pale green) of the central ring of 2',6'-carboxymethyl-cellotriose.

Table S8. Average distance between the $\mathrm{Fe}^{3+}$ ion and the $\mathrm{C} 2$ and $\mathrm{C} 3$ carbons of the central ring of $2^{\prime}, 6^{\prime}-$ carboxymethyl-cellotriose.

\begin{tabular}{c|cc} 
Carbon & Average Distance [A] & Standard deviation \\
\hline C2 & 4.55 & 0.21 \\
C6 & 5.78 & 0.19
\end{tabular}


1.3.2 Molecular models of interchain CMC-Fe ${ }^{3+}$ interactions - ion-induced chain association of two monosubstituted $C M C$ residues

a) 2'-mono/2'-mono

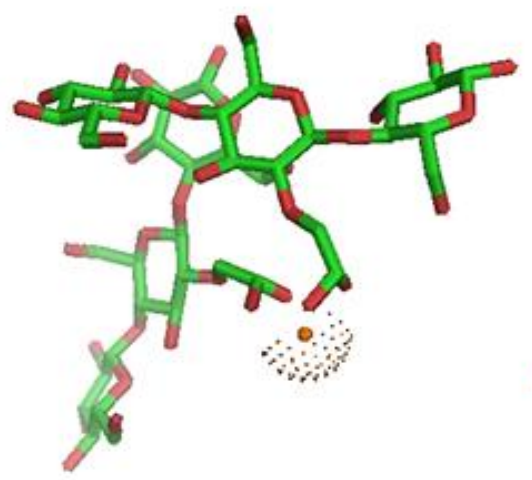

d) 2'-mono/6'-mono

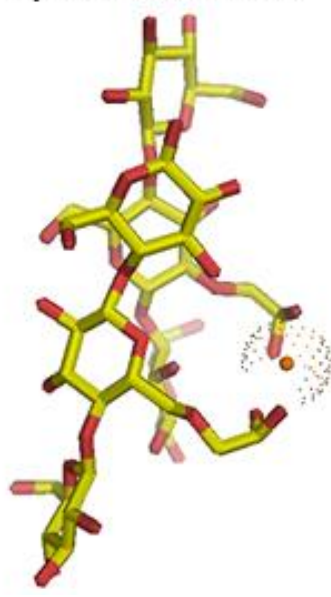

b) 2'-mono/3'-mono

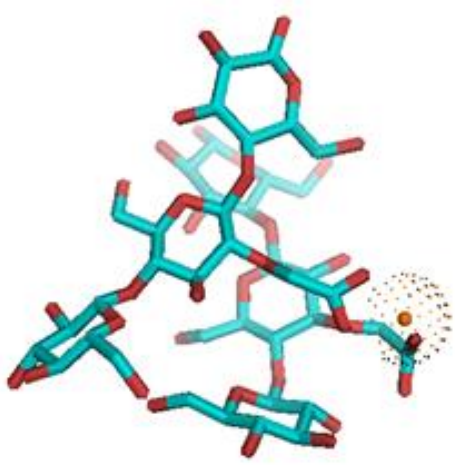

e) $3^{\prime}-$ mono/6'-mono

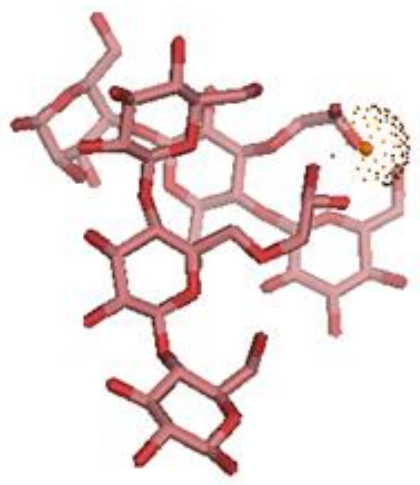

c) 3'-mono/3'-mono

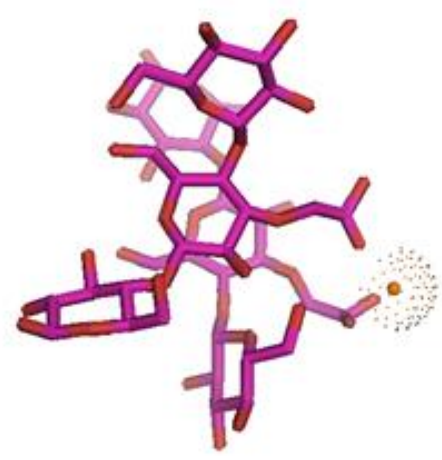

f) $6^{\prime}-$ mono/ $6^{\prime}-$ mono

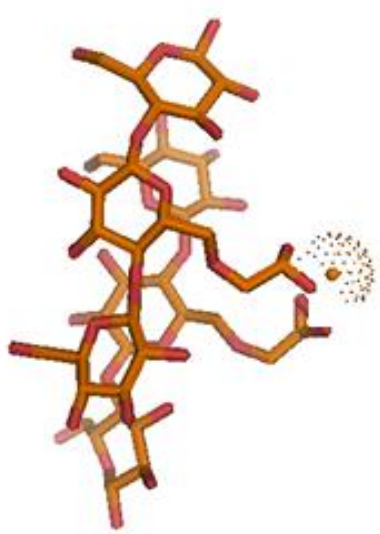

Figure S8. Final configurations of 100 ns MD trajectories simulated for (a) 2'-mono/2'-mono, (b) 2'mono/3'-mono and (c) 3'-mono/3'-mono systems, and of 200 ns trajectories simulated for (d) 2'mono/6'-mono, (e) 3'-mono/6'-mono and (f) 6'-mono/6'-mono systems. The structures have been extracted using VMD and then represented using Pymol. Carboxymethyl-cellotriose systems are represented as tubes, while the $\mathrm{Fe}^{3+}$ ion as dotted spheres. 

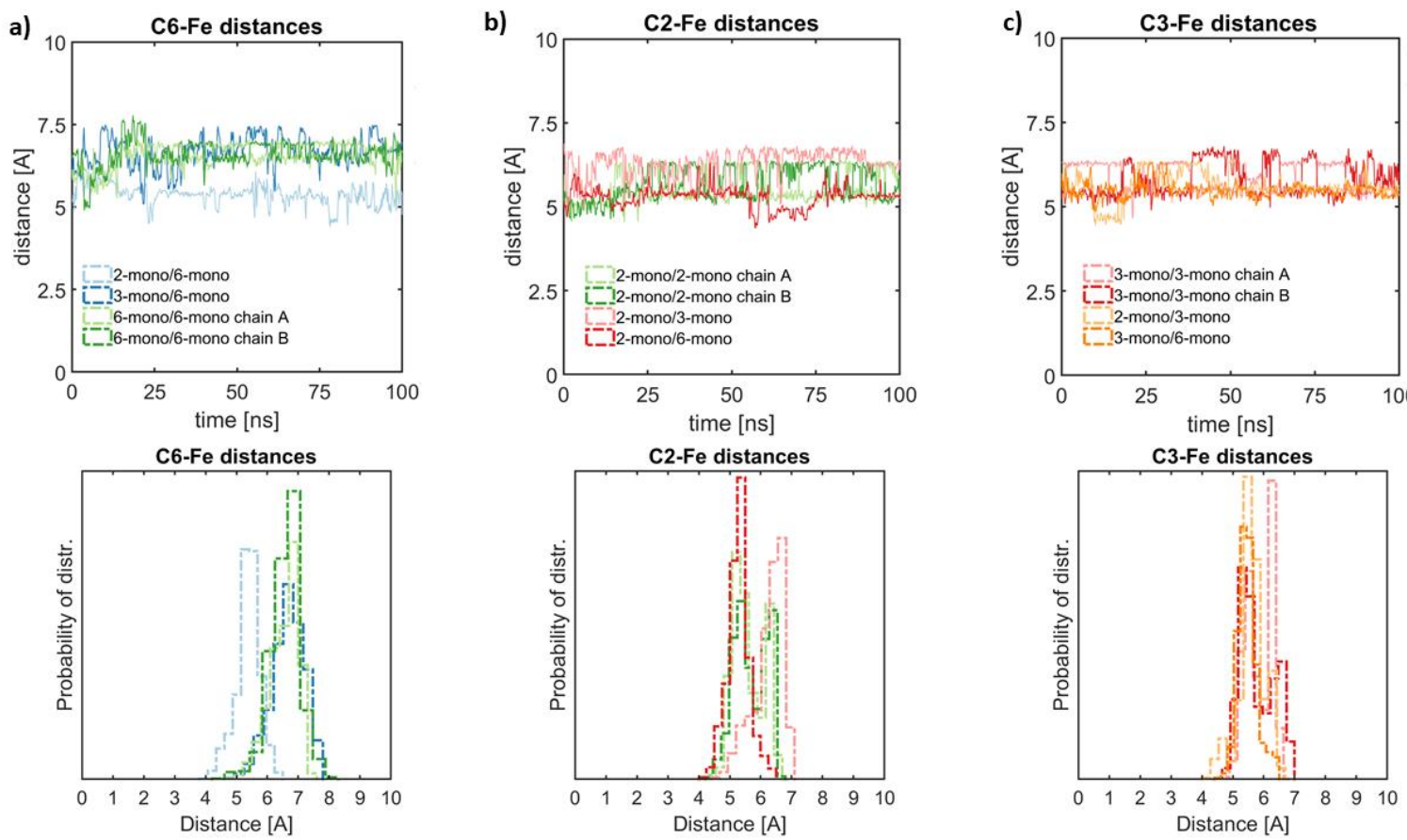

Figure 59. Evolution along the trajectory (top) and probability distribution of the distances (bottom) between $\mathrm{Fe}^{3+}$ and a) $\mathrm{C} 6$, b) C2 and c) C3 central ring carbons of monosubstituted carboxymethylcellotriose. 
Table 59. Summary of the starting orientation and alignment in MD simulations of pairs of monosubstituted carboxymethyl cellotriose systems. The numbers in brackets in the starting pose refer to the chains orientation and alignment schematically represented in Figure 6, main text.

Chains: $\quad$ Starting pose

\section{Alignment switch during}

simulation

\begin{tabular}{|l|c|c|}
\hline $\mathbf{2}^{\prime}$-mono/2'-mono & $-29.85^{\circ}(1)$ & yes \\
\hline $\mathbf{2}^{\prime}$-mono/3'-mono & $11.33^{\circ}(1)$ & yes \\
\hline $\mathbf{3}^{\prime}$-mono/3'-mono & $43.47(1)$ & yes \\
\hline $\mathbf{2}^{\prime}$-mono/6'-mono & $-47.29^{\circ}(3)$ & yes \\
\hline $\mathbf{3}^{\prime}$-mono/6'-mono & $160.46(2)$ & yes \\
\hline $\mathbf{6}^{\prime}$-mono/6'-mono & $-34.84(1)$ & yes \\
\hline
\end{tabular}
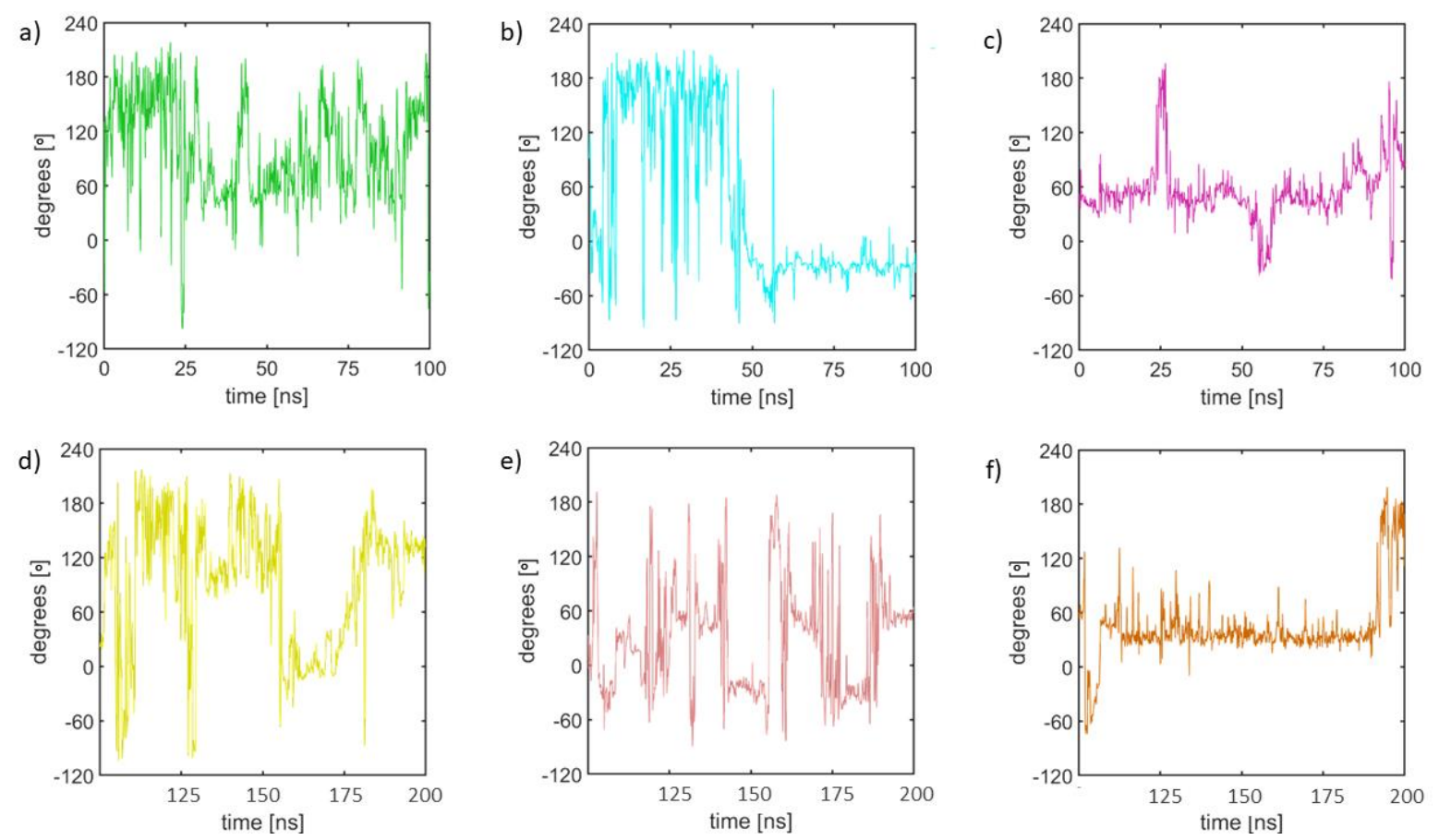

Figure S10. Time evolution along MD trajectories of the dihedral angle $\alpha$, defining the mutual orientation and alignment in a) 2'-mono/2'-mono, b) 2'mono/3'-mono, c) 3'-mono/3'-mono, d) 2'mono/6'-mono, e) 3'-mono/6'-mono and f) 6'-mono/6'-mono systems. 
Table S10. Inter-chain hydrogen bonds established in MD trajectories of the 2'-mono/3'-mono system. Only hydrogen bonds showing at least $5 \%$ occurrence throughout the trajectory were considered.

\begin{tabular}{|c|c|c|c|c|c|}
\hline System & \multicolumn{2}{|c|}{ Donor } & \multicolumn{2}{|c|}{ Acceptor } & Occurrence \\
\hline '̀ & 3'-mono & $\mathrm{HO} 2, \mathrm{c}$ & 2'-mono & $\mathrm{COO}$ & ca. 20\% \\
\hline $\begin{array}{ll}0 & 0 \\
\frac{1}{0} & \vdots\end{array}$ & 3'-mono & $\mathrm{HO} 2, \mathrm{C}$ & 2'-mono & $06, r$ & ca. $\sim 9 \%$ \\
\hline & 3'-mono & $\mathrm{HO3}, \mathrm{nr}$ & 2'-mono & $\mathrm{COO}$ & ca. $\sim 9 \%$ \\
\hline
\end{tabular}

Table S11: Inter-chain hydrogen bonds established in MD trajectories of the 3'-mono/3'-mono system. Only hydrogen bonds showing at least $5 \%$ occurrence throughout the trajectory were considered.

\begin{tabular}{|c|c|c|c|c|c|}
\hline System & \multicolumn{2}{|c|}{ Donor } & \multicolumn{2}{|c|}{ Acceptor } & Occurrence \\
\hline \multirow{2}{*}{$\begin{array}{l}0 \\
\vdots \\
\vdots \\
\xi\end{array}$} & chain A & $\mathrm{HO} 2, \mathrm{c}$ & chain B & $\mathrm{O} 2, \mathrm{nr}$ & ca. $18 \%$ \\
\hline & chain A & $\mathrm{HO} 2, \mathrm{C}$ & chain B & O6, $\mathrm{nr}$ & ca. $\sim 7 \%$ \\
\hline \multirow{2}{*}{$\begin{array}{l}\grave{n} \\
\precsim \\
\delta \\
\frac{\delta}{\delta}\end{array}$} & chain A & $\mathrm{HO} 2, \mathrm{r}$ & chain B & $03, r$ & ca. $5 \%$ \\
\hline & chain B & $\mathrm{HO} 2, \mathrm{C}$ & chain A & $\mathrm{COO}$ & $c a . \sim 11 \%$ \\
\hline in & chain B & $\mathrm{HO} 2, \mathrm{nr}$ & chain A & $\mathrm{COO}$ & ca. $\sim 9 \%$ \\
\hline
\end{tabular}

Table S12. Inter-chain hydrogen bonds established in MD trajectories of the 2'-mono/6'-mono system. Only hydrogen bonds showing at least $5 \%$ occurrence throughout the trajectory were considered.

\begin{tabular}{|c|c|c|c|c|c|}
\hline System & \multicolumn{2}{|c|}{ Donor } & \multicolumn{2}{|c|}{ Acceptor } & \multirow{2}{*}{$\begin{array}{c}\text { Occurrence } \\
\text { ca. } \sim 8 \%\end{array}$} \\
\hline 1 & 2'-mono & $\mathrm{HO} 3, r$ & 6'-mono & $06, c$ & \\
\hline 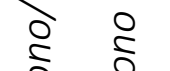 & 6'-mono & $\mathrm{HO} 2, \mathrm{r}$ & 2'-mono & $\mathrm{COO}$ & ca. 11\% \\
\hline $\begin{array}{l}\xi \\
i\end{array}$ & 6'-mono & $\mathrm{HO} 2, \mathrm{C}$ & 2'-mono & $\begin{array}{c}\mathrm{O}_{\text {glyc }} \\
(\mathrm{nr}->\mathrm{c})\end{array}$ & ca. 10\% \\
\hline
\end{tabular}


Table S13. Inter-chain hydrogen bonds established in MD trajectories of the 6'-mono/6'-mono system. Only hydrogen bonds showing at least $5 \%$ occurrence throughout the trajectory were considered.

\begin{tabular}{|c|c|c|c|c|c|}
\hline System & \multicolumn{2}{|c|}{ Donor } & \multicolumn{2}{|c|}{ Acceptor } & Occurrence \\
\hline \multirow{3}{*}{$\begin{array}{ll}1 & \\
\vdots & \\
o & 0 \\
\vdots & \vdots \\
\frac{1}{1} & \xi\end{array}$} & chain A & HO3, r & chain B & $\mathrm{COO}$ & ca. 35\% \\
\hline & chain A & HO6, nr & chain B & $\mathrm{O} 2, \mathrm{c}$ & ca. $\sim 5 \%$ \\
\hline & chain B & $\mathrm{HO} 2, \mathrm{r}$ & chain A & $\mathrm{COO}$ & ca. 20\% \\
\hline
\end{tabular}


Table S14. Summary of the intra-chain hydrogen bonds established by each of the investigated system during the MD simulations. Formation of hydrogen bond with high occurrence is represented by the tick, while the hyphen represents hydrogen bonds that are not observed. The red $x$ denotes the intrachain hydrogen bonds that could not be established due to the carboxymethyl substitution.

\begin{tabular}{|c|c|c|c|c|c|c|}
\hline & $\begin{array}{l}\text { O5, nr- } \\
\text { HO3, c }\end{array}$ & $\begin{array}{l}\text { O5, c- } \\
\text { HO3, r }\end{array}$ & $\begin{array}{c}\mathrm{HO2}, \mathrm{nr}- \\
06, \mathrm{c}\end{array}$ & $\begin{array}{l}\text { O2, nr- } \\
\text { H06, c }\end{array}$ & $\begin{array}{c}\mathrm{HO2}, \mathrm{c}- \\
06, \mathrm{r}\end{array}$ & $\begin{array}{l}\text { O2, c- } \\
\text { HO6, r }\end{array}$ \\
\hline \multirow{2}{*}{$\begin{array}{c}2^{\prime}- \\
\text { mono } \\
2^{\prime}- \\
\text { mono }\end{array}$} & $\sqrt{ }$ & $\sqrt{ }$ & - & - & $x$ & - \\
\hline & $\boldsymbol{V}$ & $\boldsymbol{V}$ & - & - & $x$ & - \\
\hline \multirow{2}{*}{$\begin{array}{c}2^{\prime}- \\
\text { mono } \\
3^{\prime}- \\
\text { mono }\end{array}$} & $\sqrt{ }$ & $\sqrt{ }$ & - & - & $x$ & - \\
\hline & $x$ & $\sqrt{ }$ & - & - & - & - \\
\hline \multirow{2}{*}{$\begin{array}{c}3^{\prime}- \\
\text { mono } \\
3^{\prime}- \\
\text { mono }\end{array}$} & $x$ & $\sqrt{ }$ & - & - & - & - \\
\hline & $x$ & $\sqrt{ }$ & - & - & - & - \\
\hline \multirow{2}{*}{$\begin{array}{c}2^{\prime}- \\
\text { mono } \\
6^{\prime}- \\
\text { mono }\end{array}$} & $\boldsymbol{V}$ & $\boldsymbol{V}$ & - & - & $\mathbf{X}$ & - \\
\hline & $\boldsymbol{V}$ & $\boldsymbol{V}$ & - & $x$ & - & - \\
\hline \multirow{2}{*}{$\begin{array}{c}3^{\prime}- \\
\text { mono } \\
6 '- \\
\text { mono }\end{array}$} & $x$ & $\sqrt{ }$ & - & - & - & - \\
\hline & $\sqrt{ }$ & $\sqrt{ }$ & - & $x$ & - & - \\
\hline \multirow{2}{*}{$\begin{array}{c}6^{\prime}- \\
\text { mono } \\
6^{\prime}- \\
\text { mono }\end{array}$} & $\boldsymbol{V}$ & $\sqrt{ }$ & - & $x$ & - & - \\
\hline & $\mathbf{V}$ & $\boldsymbol{V}$ & - & $x$ & - & - \\
\hline
\end{tabular}




\section{References}

1) Kono, H.; Oshima, K.; Hashimoto, H.; Shimizu, Y.; Tajima, K. NMR characterization of sodium carboxymethyl cellulose: Substituent distribution and mole fraction of monomers in the polymer chains. Carbohydr. Polym. 2016, 146, 1-9.

2) Kono, H.; Oshima, K.; Hashimoto, H.; Shimizu, Y.; Tajima, K. NMR characterization of sodium carboxymethyl cellulose 2: Chemical shift assignment and conformation analysis of substituent groups. Carbohydr. Polym. 2016, 150, 241-249.

3) Kono, H.; Anai, H.; Hashimoto, H.; Shimizu, Y. 13C-detection two-dimensional NMR approaches for cellulose derivatives. Cellulose 2015, 22, 2927-2942.

4) Kono, H. $1 \mathrm{H}$ and $13 \mathrm{C}$ chemical shift assignment of the monomers that comprise carboxymethyl cellulose. Carbohydr. Polym. 2013, 97, 384-390.

5) Ambjörnsson, H. A.; Schenzel, K.; Germgård, U. Carboxymethyl Cellulose Produced at Different Mercerization Conditions and Characterized by NIR FT Raman Spectroscopy in Combination with Multivariate Analytical Methods. BioResources 2013, 8, 1918-1932. 